\title{
Johannes Pitz, Atsushi Kawada and Jeffrey A Schwab: Patent Litigation in Germany, Japan and the United States: A Practitioner's Guide
}

\author{
Verlag C.H. Beck, Munich 2015. pp. XV + 207. \\ ISBN 978-3-406-65075-8. €190.00
}

\section{Christopher Heath}

Published online: 25 April 2016

(C) Max Planck Institute for Innovation and Competition, Munich 2016

A slim and elegant book that in great clarity sets out the details of how to enforce patents in three major jurisdictions: Germany, the US and Japan. In doing so, the book does not follow a country-by-country approach, but takes the reader chronologically through the different phases of a patent dispute and in this context lists the specifics of each of the three jurisdictions. The book's chapters discuss the following: scope of patent protection, fact finding, claim interpretation, pre-trial issues, trial, principles of procedure, and comparative aspects.

Although conceived as a guide for practitioners, the book comes up to academic standards due to the ample references to academic writings and court decisions. Particularly for the parts dealing with Japan, the clear and concise style of writing should be mentioned as unfortunately, incomprehensible English these days has become the trade mark of many Japanese writings and the semi-official translations of decisions published by the IP High Court.

All three authors are well-reputed practitioners in their jurisdiction and vouch for reliable, up-to-date information. Particularly noteworthy in this respect are the parts on US pre-trial discovery, the Japanese double-track litigation system and the comparative remarks set out in the last chapter.

The book is thus a welcome and reliable addition to the literature on comparative patent litigation.

C. Heath $(\bowtie)$

Dr. jur.; Member of the Boards of Appeal of the European Patent Office

Munich, Germany

e-mail: blitzblitzblau@web.de 